\title{
Evaluation of carbon dioxide rebreathing during exercise assisted by noninvasive ventilation with plateau exhalation valve
}

This article was published in the following Dove Press journal:

International Journal of COPD

16 January 2017

Number of times this article has been viewed

\author{
Yong-er Ou* \\ Zhi-min Lin* \\ Dong-ming Hua \\ Ying Jiang \\ Ya-ting Huo \\ Qun Luo \\ Rong-Chang Chen
}

State Key Laboratory of Respiratory Disease, National Clinical

Research Center for Respiratory

Disease, Guangzhou Institute of

Respiratory Disease, First Affiliated

Hospital of Guangzhou Medical

University, Guangzhou, People's

Republic of China

*These authors contributed equally to this work
Correspondence: Rong-Chang Chen State Key Laboratory of Respiratory Disease, National Clinical Research Center for Respiratory Disease, Guangzhou Institute of Respiratory Disease, First Affiliated Hospital of Guangzhou Medical University, I5 I Yanjiang Road, Guangzhou, Guangdong 510120 , People's Republic of China Tel/fax +86208306 2882 Email rcchengird@।63.com
Abstract: Noninvasive ventilation with a plateau exhalation valve (PEV) is often used as an adjunct to exercise to achieve a physiologic training effect in severe chronic obstructive pulmonary disease (COPD) patients. However, during exercise, with the increase of exhalation flow and respiratory rate and limited capability of PEV to exhale gases out of the circuit, it is still unknown whether $\mathrm{CO}_{2}$ rebreathing occurs in COPD patients ventilated during exercise assisted by single-limb circuit with a PEV. A maximal symptom-limited cycle exercise test was performed while ventilated on pressure support (inspiratory:expiratory pressure 14:4 $\mathrm{cmH}_{2} \mathrm{O}$ ) in 18 male patients with stable severe COPD (mean \pm standard deviation, forced expiratory volume in $1 \mathrm{~s}: 29.5 \% \pm 6.9 \%$ predicted). At rest and during exercise, breathing pattern, mean expiratory flow, mean expiratory flow of $\mathrm{PEV}$, and the mean inspiratory fraction of $\mathrm{CO}_{2}$ (tidal fractional concentration of inspired $\mathrm{CO}_{2}\left[\mathrm{FiCO}_{2}\right]$ ) reinsufflated from the circuit was measured for each breath. In comparison with rest, with the significant increase of mean expiratory flow $(0.39 \pm 0.15$ vs $0.82 \pm 0.27 \mathrm{~L} / \mathrm{s})$, fractional concentration of end-tidal $\mathrm{CO}_{2}(2.6 \% \pm 0.7 \%$ vs $5.5 \% \pm 0.6 \%)$, and the significant decrease of mean expiratory flow of PEV $(0.41 \pm 0.02$ vs $0.39 \pm 0.03 \mathrm{~L} / \mathrm{s})$, tidal $\mathrm{FiCO}_{2}$ significantly increased at peak exercise $(0.48 \% \pm 0.19 \%$ vs $1.8 \% \pm 0.6 \%)$ in patients with stable severe COPD. The inflection point of obvious $\mathrm{CO}_{2}$ rebreathing was $0.67 \pm 0.09 \mathrm{~L} / \mathrm{s}(95 \%$ confidence interval $0.60-0.73 \mathrm{~L} / \mathrm{s}$ ). Ventilated by a single-limb tubing with $\mathrm{PEV}$ caused $\mathrm{CO}_{2}$ rebreathing to COPD patients during exercise. Patients with mean expiratory flow $>0.60-0.73 \mathrm{~L} / \mathrm{s}$ may be predisposed to a higher risk of $\mathrm{CO}_{2}$ rebreathing.

Keywords: carbon dioxide rebreathing, noninvasive ventilation, exercise, chronic obstructive pulmonary disease, single-limb circuit, pulmonary rehabilitation

\section{Introduction}

Exercise training is a key component of pulmonary rehabilitation. It has demonstrated significant improvements in both exercise tolerance and quality of life in patients with chronic obstructive pulmonary disease (COPD). ${ }^{1}$ The intensity of exercise training is of great importance to yield a true physiologic effect. However, in patients with severe COPD, exertional dyspnea and leg fatigue make it impossible for the patient to maintain intensity of training for enough time to achieve a physiologic training effect. ${ }^{2}$ Noninvasive ventilation (NIV) has been reported to be used as support for exercise to improve exercise tolerance and respiratory performances in patients with mild-to-severe COPD with inconsistent results. ${ }^{3-20}$ In these studies, one of the obvious methodological issues existed with respect to the selection of exhalation valve connected to the single-limb circuit. Evidence from Moga et $\mathrm{al}^{19}$ and Highcock et $\mathrm{al}^{20}$ indicated that NIV with a single-limb circuit 
with Whisper Swivel II expiratory valve (Respironics Inc., Murrysville, PA, USA) assisting exercise did not improve exercise capacity in COPD patients. Also, as previously reported by Ferguson and Gilmartin, ${ }^{21}$ the use of Whisper Swivel II expiratory valve during bi-level positive airway pressure (BiPAP) ventilatory assistance causes $\mathrm{CO}_{2}$ rebreathing, which can blunt any effect of BiPAP on partial pressure of $\mathrm{CO}_{2}\left(\mathrm{PaCO}_{2}\right)$. It could not be dismissed that $\mathrm{CO}_{2}$ rebreathing occurred with the use of the standard exhalation port thus diminishing the efficacy of NIV support. Plateau exhalation valve (PEV) or the Sanders NRV-2 plateau valve (NRV; Respironics Inc.) have been shown to be more effective in eliminating $\mathrm{CO}_{2}$ rebreathing in patients at rest, ${ }^{21}$ however, the latter one prevented $\mathrm{CO}_{2}$ rebreathing at the expense of increased expiratory resistance and work of breathing ${ }^{22}$ and sometimes it can potentially malfunction; considering these factors, the former one has been widely used.

With the use of the PEV in the circuit, the risk of $\mathrm{CO}_{2}$ rebreathing is presumably low when the expiratory time (Te) is long enough to ensure that evacuation of the circuit is complete. However, our group have previously demonstrated that the mean leak flow of the valve at low pressure (expiratory phase) was $0.43 \mathrm{~L} / \mathrm{s}$ at rest. ${ }^{23}$ During exercise, the increase of expiratory flow due to the high levels of ventilatory requirements, and elevated breathing frequency of patients with $\mathrm{COPD}$, may promote the occurrence of $\mathrm{CO}_{2}$ rebreathing. As $\mathrm{CO}_{2}$ rebreathing increases the drive to ventilate and the work of breathing ${ }^{22,24,25}$ and may have a negative impact on efficacy, ${ }^{26,27}$ it is important to clarify this risk.

Therefore, the aim of the present study was to evaluate whether $\mathrm{CO}_{2}$ rebreathing occurred in COPD patients ventilated during exercise by the single-limb circuit with a PEV and to estimate a potential threshold of expiratory flow for predicting $\mathrm{CO}_{2}$ rebreathing.

\section{Methods}

\section{Study participants}

Eighteen COPD patients were recruited from the first affiliated hospital of Guangzhou Medical University from January 2016 to March 2016. The diagnosis of COPD was confirmed by physician's diagnosis and spirometry. Patients who presented with clinical stability (no exacerbation in the previous 4 weeks and with no change in medications, in the absence of right heart decompensation signs), forced expiratory volume in $1 \mathrm{~s}\left(\mathrm{FEV}_{1}\right)<50 \%$ predicted, dyspnea as a main symptom that limited daily activities, were included in the study. Excluded criteria: individuals with obvious pulmonary bullae or facial trauma/malformation; cardiovascular disease; a history of uncontrolled hypertension; other respiratory diseases; oxygen saturation $\left(\mathrm{SpO}_{2}\right)<88 \%$ at rest; patients with musculoskeletal or neurologic disorders. Ethical approval for this study was obtained from the research ethics committee of the First Affiliated Hospital of Guangzhou Medical University, and all participants gave their written informed consent in accordance with the Helsinki Declaration.

\section{Study design}

Patients completed screening tests to determine eligibility for the study. This study comprised of two visits: 1) Visit 1 included a thorough clinical assessment, pulmonary function tests, baseline arterial blood gas sampling, getting used to the application of the ventilator, and completing a maximal symptom-limited-incremental cardiopulmonary exercise test; 2) Visit 2 included a maximal cycle exercise test with the participants assisted by BiPAP (Vision; Respironics Inc.) receiving $10 \mathrm{cmH}_{2} \mathrm{O}$ pressure support in addition to oxygen therapy. At rest and during the whole exercise process, breathing pattern, heart rate (HR), flow, pressure, $\mathrm{CO}_{2}$ concentration, and $\mathrm{SpO}_{2}$ were recorded until complete recovery. Before each visit, subjects kept on taking regular medicine and abstained from caffeine, heavy meals, alcohol, and major physical exertion entirely on visit days.

\section{Pulmonary function tests}

Pulmonary function tests were performed using a Quark PFT (pulmonary function testing) system (Cosmed, Rome, Italy). $\mathrm{FEV}_{1}$ and forced vital capacity (FVC) were determined from the best of three maneuvers if the variance was within $150 \mathrm{~mL}$ or $5 \%$ of the $\mathrm{FEV}_{1}$ or FVC, respectively. ${ }^{28}$ Measurements were expressed as percentages of predicted normal values. ${ }^{29-31}$

\section{Oxygen delivery and ventilator setting}

Oxygen was delivered to the face mask by a tube at a constant rate $(5 \mathrm{~L} / \mathrm{min})$. Ventilatory assistance was delivered using a BiPAP Vision with a PEV in BiPAP spontaneous/time mode applied via a tightly fitting full face mask (Curative, Beijing, People's Republic of China). Inspiratory positive airway pressure (IPAP) was set at $14 \mathrm{cmH}_{2} \mathrm{O}$, and the expiratory positive airway pressure (EPAP) was set at $4 \mathrm{cmH}_{2} \mathrm{O}$ and a backup respiratory frequency was set at 12 breaths/min.

\section{Maximal cycle exercise test and intervention procedure}

Maximal symptom-limited-incremental cycle exercise tests were conducted on an electronically braked cycle ergometer (Ergoselect 200 K; Cosmed, Rome, Italy). Symptom-limited 


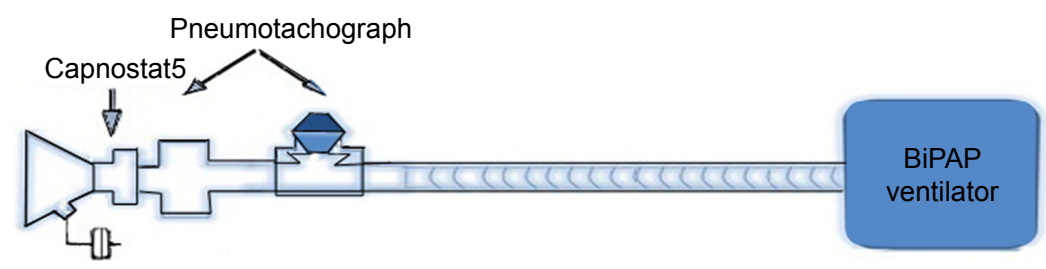

Airway pressure

Figure I Experimental setup.

Notes: The facemask was attached in series with capnostat5 (mainstream $\mathrm{CO}_{2}$ sensor), pneumotachograph, PEV (flow of the PEV was directly recorded by a pneumotachograph), ventilator tubing, and BiPAP machine. Airway pressure and flow and the volume of $\mathrm{CO}_{2}$ delivered from the circuit at each breath were measured at the distal end of the ventilator circuit. Furthermore, to evaluate the leak flow of the PEV, another pneumotachograph was attached to the PEV.

Abbreviations: BiPAP, bi-level positive airway pressure; PEV, plateau exhalation valve.

cycle exercise test consisted of a steady-state resting period of at least $3 \mathrm{~min}$ followed by 1 min of unloaded pedaling at $60-65$ cycles/min; the load was increased by $10 \mathrm{~W}$ each minute, starting at $10 \mathrm{~W}$ until a symptom-limited endpoint. At rest and during exercise, participants breathed through the facemask attached in series with capnostat5 (Phillips Respironics, Murrysville, PA, USA), pneumotachograph (3830A series; Hans-Rudolph Inc., Shawnee Mission, KS, USA), PEV (flow of the PEV was directly recorded by a pneumotachograph [ADInstruments Inc., Sydney, Australia]), ventilator tubing, and BiPAP ventilator (Figure 1). Mouth pressure was determined using differential pressure transducers (YH; Ying Hui Medical Devices Co. Ltd., Guangzhou, People's Republic of China) connected to pressure catheters attached to a mask side port. Capnostat5 attached to the Powerlab via NT1D Handheld $\mathrm{CO}_{2} / \mathrm{SpO}_{2}$ monitor (Newtech Inc., Shenzhen, People's Republic of China). The delay representing transit time from the sample point to the analyzer was measured beforehand. Signals of pressure, flow, and $\mathrm{CO}_{2}$ were recorded at a frequency of 200, 200, and $100 \mathrm{~Hz}$, respectively. Signals were recorded continuously using an analogic/numeric Powerlab data acquisition system (ML796; ADInstruments Inc.) running on an iMac computer (Apple Computer Inc., Cupertino, CA, USA). The flow signal was integrated to yield the volume.

Analyses were made breath by breath, after phasing $\mathrm{CO}_{2}$ curves with flow and pressure. For each breath, inspiratory time (Ti), Te, respiratory rate (RR), inspiratory tidal volume (Vti), expiratory tidal volume (Vte), mean expiratory flow (Vte/Te), mean flow vented out from the PEV during expiration $(\mathrm{Ex} / \mathrm{Te})$, fractional concentration of inspired $\mathrm{CO}_{2}\left(\mathrm{FiCO}_{2}\right)$, and fractional concentration of end-tidal $\mathrm{CO}_{2}\left(\mathrm{FetCO}_{2}\right)$ were measured. The volume of $\mathrm{CO}_{2}$ delivered from the circuit at each breath was calculated by integrating the $\mathrm{CO}_{2}$ flow curve, defined as the product of inspiratory flow and $\mathrm{CO}_{2}$ concentration curves. ${ }^{32}$ Mean inspiratory fraction of $\mathrm{CO}_{2}$ for each tidal volume (tidal $\mathrm{FiCO}_{2}$ ), expressed as a percentage, was defined as: inspired volume of $\mathrm{CO}_{2} / \mathrm{Vti}^{*} 100$.

Using Origin Pro 8 software to draw a scatter plot to determine the relationship between Vte/Te (x values) and the tidal $\mathrm{FiCO}_{2}$ (y values), apply a nonlinear curve fit to the scatter plot, if the nonlinear curve fitness was good (adjusted $R^{2} \geq 0.8, P<0.05$ ), the presence of an inflection point was next determined by assuming that the Vte/Te-tidal $\mathrm{FiCO}_{2}$ curve was made up of two straight lines and that the inflection point represented the point where these lines intersected, to find out the obvious inflection point when $\mathrm{CO}_{2}$ rebreathing appeared. The curve was divided into two parts $(A \& B)$ at an arbitrary point, $V_{k}$, and a pair of linear regressions were performed using the data above and below this point. This yielded two regression lines, line $\mathrm{A}$ and line $\mathrm{B}$, with correlation coefficients, $\mathrm{rA}$ and $\mathrm{rB}$, respectively. The process was repeated many times varying the dividing point $\mathrm{V}_{\mathrm{k}}$ so that the point where $\mathrm{rA}^{*} \mathrm{rB}$ was maximal could be determined.

Fingertip $\mathrm{SpO}_{2}$ was measured by pulse oximetry; HR was measured by six-lead electrocardiogram; blood pressure was measured by automatic blood pressure measurement with an arm cuff during the whole process.

\section{Statistical analysis}

Data were expressed as mean \pm standard deviation after testing for normal distribution (Kolmogorov-Smirnov test) unless otherwise specified. The 95\% confidence interval (95\% CI) was determined if appropriate. All data were analyzed using paired $t$-test. Differences were considered significant when $P<0.05$.

\section{Results}

In total, 18 patients with stable severe COPD completed the tests; demographic data of the 18 patients are shown in Table 1. Only one COPD patient had chronic hypercapnic respiratory failure. 
Table I Characteristics of study subjects

\begin{tabular}{|c|c|}
\hline Male:Female (n) & $18: 0$ \\
\hline Age (years) & $69.3 \pm 1.4$ \\
\hline Height $(\mathrm{cm})$ & $165.6 \pm 1.2$ \\
\hline Weight (kg) & $60.2 \pm 1.9$ \\
\hline BMI $\left(\mathrm{kg} / \mathrm{m}^{2}\right)$ & $22.0 \pm 0.6$ \\
\hline $\mathrm{FEV}_{1}(\mathrm{~L})$ & $0.77 \pm 0.04$ \\
\hline $\mathrm{FEV}_{1}$ (\% predicted) & $29.5 \pm 1.6$ \\
\hline $\mathrm{FEV}_{1} / \mathrm{FVC}(\%)$ & $35.0 \pm 1.5$ \\
\hline $\mathrm{FVC}(\mathrm{L})$ & $2.22 \pm 0.11$ \\
\hline FVC (\% predicted) & $65.5 \pm 2.95$ \\
\hline $\mathrm{MVV}(\mathrm{L} / \mathrm{min})$ & $33.4 \pm 1.6$ \\
\hline MVV (\% predicted) & $32.8 \pm 1.8$ \\
\hline Peak watt $(\mathrm{W})$ & $56.3 \pm 16.1$ \\
\hline Peak $\mathrm{VO}_{2} / \mathrm{kg}(\mathrm{mL} / \mathrm{min} / \mathrm{kg})$ & $13.4 \pm 2.9$ \\
\hline Peak $\mathrm{VO}_{2}(\%$ predicted $)$ & $47.1 \pm 12.0$ \\
\hline Peak VE (L/min) & $28.2 \pm 6.5$ \\
\hline Resting RR (breath/min) & $18.7 \pm 3.0$ \\
\hline Peak RR (breath/min) & $29.2 \pm 5.8$ \\
\hline Peak tidal volume (L) & $0.99 \pm 0.25$ \\
\hline Peak HR (beat/min) & $115.1 \pm 11.6$ \\
\hline $\mathrm{PaCO}_{2}(\mathrm{mmHg})$ & $40.7 \pm 4.4$ \\
\hline
\end{tabular}

Note: Results are reported as mean \pm standard deviation after testing for normal distribution (Kolmogorov-Smirnov test).

Abbreviations: $\mathrm{BMI}$, body mass index; $\mathrm{FEV}_{1}$, forced expiratory volume in I s; FVC, forced vital capacity; HR, heart rate; MVV, maximal voluntary ventilation; $\mathrm{RR}$, respiratory rate; $\mathrm{VE}$, minute ventilation; $\mathrm{VO}_{2}$, oxygen uptake; $\mathrm{PaCO}_{2}$, partial pressure of $\mathrm{CO}_{2}$.

Table 2 Comparison of breath characteristics at rest and peak exercise in COPD patients

\begin{tabular}{lll}
\hline & \multicolumn{2}{l}{ COPD patients } \\
\cline { 2 - 3 } & At rest & Peak-exercise \\
\hline IPAP $\left(\mathrm{cmH}_{2} \mathrm{O}\right)$ & $14.1 \pm 1.2$ & $13.6 \pm 2.0$ \\
EPAP $\left(\mathrm{cmH}_{2} \mathrm{O}\right)$ & $4.1 \pm 0.2$ & $4.5 \pm 0.4^{\$}$ \\
$\mathrm{Vte} / \mathrm{Te}(\mathrm{L} / \mathrm{s})$ & $0.39 \pm 0.15$ & $0.82 \pm 0.27^{\$}$ \\
Tidal FiCO $(\%)$ & $0.48 \pm 0.19$ & $1.8 \pm 0.6^{\$}$ \\
FetCO $(\%)$ & $2.6 \pm 0.7$ & $5.5 \pm 0.6^{\$}$ \\
Ex/Te $(\mathrm{L} / \mathrm{s})$ & $0.41 \pm 0.02$ & $0.39 \pm 0.03^{\$}$ \\
$\mathrm{Ti}(\mathrm{s})$ & $0.67 \pm 0.12$ & $0.98 \pm 0.22^{\$}$ \\
$\mathrm{Te}(\mathrm{s})$ & $2.59 \pm 0.75$ & $1.53 \pm 0.29^{\$}$ \\
$\mathrm{Vte}(\mathrm{L})$ & $0.92 \pm 0.27$ & $1.21 \pm 0.31^{\$}$ \\
Ex vol $(\mathrm{L})$ & $1.06 \pm 0.31$ & $0.61 \pm 0.13^{\$}$ \\
$\mathrm{Ti} / \mathrm{Ttot}(\%)$ & $0.28 \pm 0.05$ & $0.31 \pm 0.05$ \\
$\mathrm{RR}($ breath/min) & $17.9 \pm 4.9$ & $27.9 \pm 4.9^{\$}$ \\
SpO $(\%)$ & $98.0 \pm 1.2$ & $88.8 \pm 2.0^{\$}$ \\
$\mathrm{HR}($ beat/min) & $88.5 \pm 10.6$ & $119.7 \pm 8.8^{\$}$ \\
Systolic blood pressure $(\mathrm{mmHg})$ & $120.3 \pm \mathrm{II} .9$ & $174.1 \pm 8.5^{\$}$ \\
Diastolic blood pressure $(\mathrm{mmHg})$ & $71.5 \pm \mathrm{II} .2$ & $87.2 \pm 8.5^{\$}$ \\
\hline
\end{tabular}

Notes: Results are reported as mean \pm standard deviation after testing for normal distribution (Kolmogorov-Smirnov test). ${ }^{\$} P<0.0$ l peak-exercise vs at rest.

Abbreviations: COPD, chronic obstructive pulmonary disease; EPAP, expiratory positive airway pressure; Ex vol, the volume vented out from the exhalation valve during expiration; Ex/Te, the mean flow vented out from the plateau exhalation valve during expiration; FetCO $\mathrm{C}_{2}$, fractional concentration of end-tidal $\mathrm{CO}_{2} ; \mathrm{HR}$, heart rate; IPAP, inspiratory positive airway pressure; $\mathrm{RR}$, respiratory rate; $\mathrm{SpO}_{2}$, oxygen saturation; Te, expiratory time; $\mathrm{Ti}$, inspiratory time; $\mathrm{Ti} / \mathrm{T}$ tot, inspiratory duty cycle; Tidal $\mathrm{FiCO}_{2}$, mean inspiratory fraction of $\mathrm{CO}_{2}$; Vte, expiratory tidal volume; $\mathrm{Vte} / \mathrm{Te}$, mean expiratory flow.

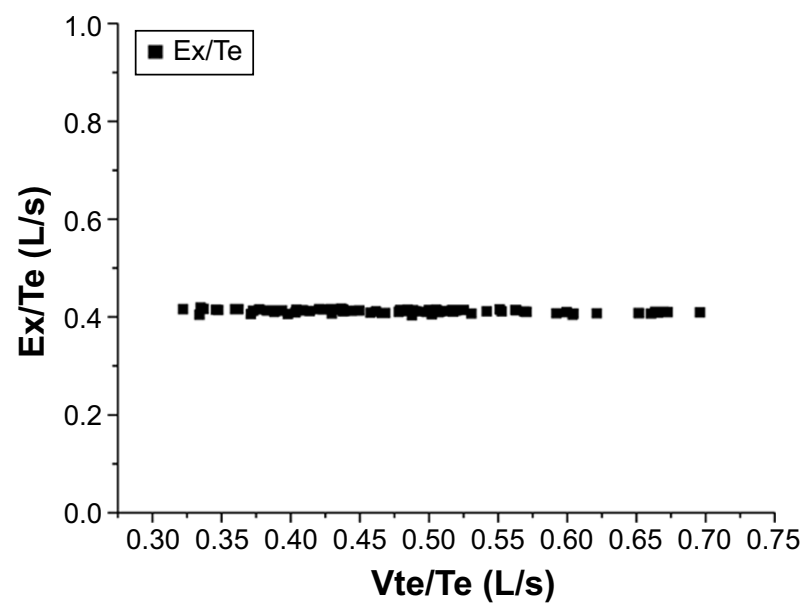

Figure 2 The changes of Ex/Te varied with $\mathrm{Vte} / \mathrm{Te}$ throughout rest and exercise periods in one representative subject.

Abbreviations: Ex/Te, mean flow vented out from the plateau exhalation valve during expiration; $\mathrm{Vte} / \mathrm{Te}$, mean expiratory flow.

As can be seen from Table 2, while ventilated on pressure support (inspiratory:expiratory pressure 14:4 $\mathrm{cmH}_{2} \mathrm{O}$ ) assisted by single-limb circuit with a PEV, in comparison with rest, at peak exercise, with the increase of expiratory tidal volume, elevated breathing frequency, Vte/Te and FetCO ${ }_{2}$, and the decrease of Ex/Te and Te, tidal $\mathrm{FiCO}_{2}$ significantly increased (all $P<0.01$ ).

During expiration, with the increase of $\mathrm{Vte} / \mathrm{Te}$, the mean flow vented out from PEV varied from 0.41 to $0.39 \mathrm{~L} / \mathrm{s}$ throughout exercise in COPD patients (Table 2; Figure 2).

Throughout rest and exercise, tidal $\mathrm{FiCO}_{2}$ varied with $\mathrm{Vte} / \mathrm{Te}$ in all subjects. In the majority of COPD patients, tidal $\mathrm{FiCO}_{2}$ increased with increasing Vte/Te. After using Origin Pro 8 software to draw a scatter plot to determine the relationship between the Vte/Te ( $\mathrm{x}$ values) and the tidal $\mathrm{FiCO}_{2}$ (y values), applying a nonlinear curve fit to the scatter plot (Figure 3A), the curve fitness was good (adjusted $R^{2}>0.80$, $P<0.05)$ in 15 subjects. However, three of the COPD patients with their $\mathrm{FEV}_{1}$ of $0.49,0.52$, and $0.61 \mathrm{~L}$ failed the curve fitness (adjusted $R^{2}<0.05$; Figure 3B). The inflection point of obvious $\mathrm{CO}_{2}$ rebreathing was $0.67 \pm 0.09 \mathrm{~L} / \mathrm{s}(95 \%$ CI: $0.60-0.73 \mathrm{~L} / \mathrm{s}$; Figure 4).

\section{Discussion}

Exercise training is a key component of pulmonary rehabilitation. In patients with severe COPD, exertional dyspnea makes it impossible for the patient to maintain intensity of training for enough time to achieve a physiologic training effect. ${ }^{2}$ NIV has been reported to be used as support for exercise to improve exercise tolerance and respiratory performances in patients with mild-to-severe COPD, with 

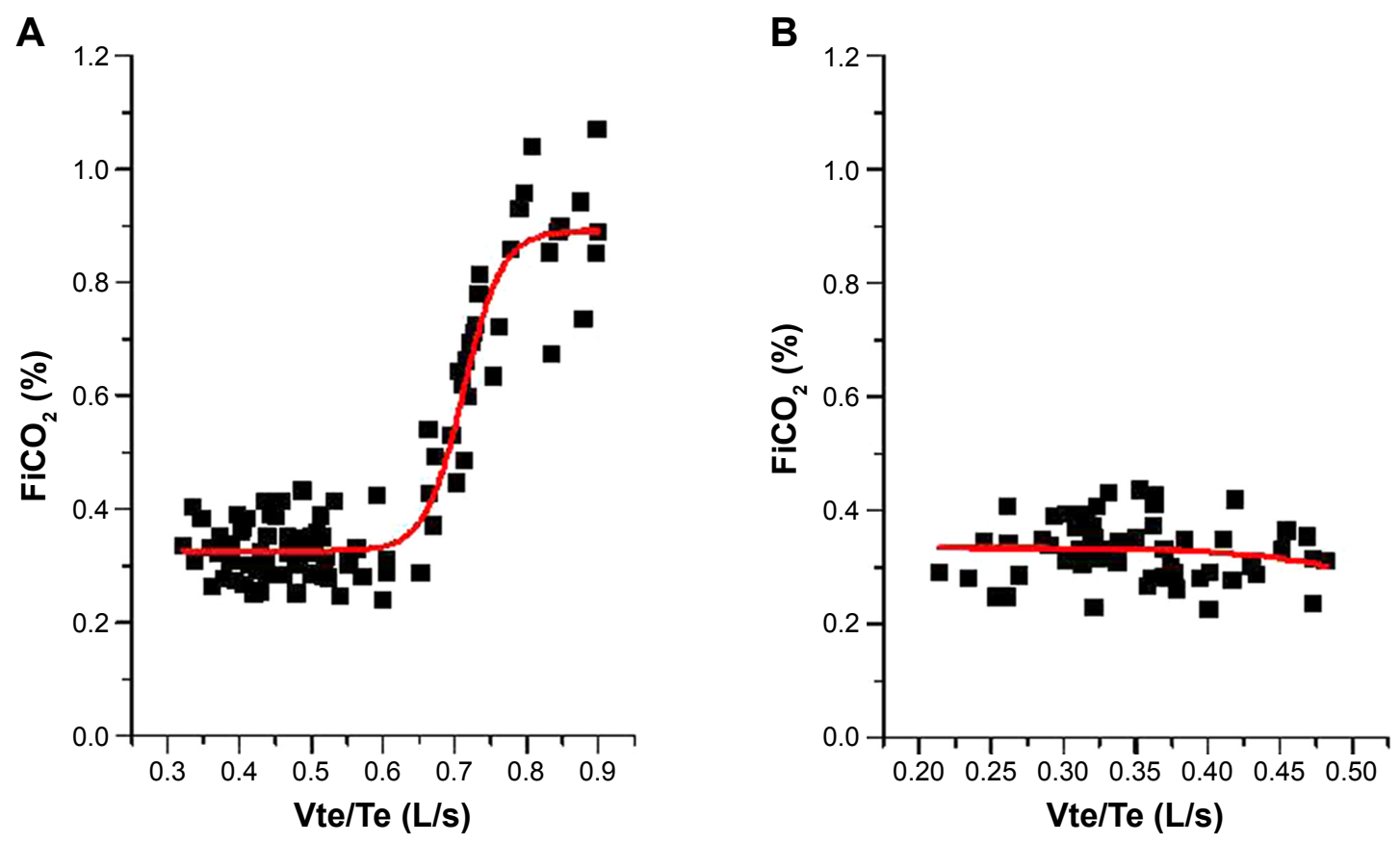

Figure 3 The changes of tidal $\mathrm{FiCO}_{2}$ varied with $\mathrm{Vte} / \mathrm{Te}$ throughout rest and exercise periods in two representative subjects (A, B).

Notes: (Ш) Data points are mean values of the expiratory tidal flow and fraction of inspired $\mathrm{CO}_{2}$ of the next breath for respective subjects. (-) represents the curve that fits the scatter plot.

Abbreviations: $\mathrm{FiCO}_{2}$, fractional concentration of inspired $\mathrm{CO}_{2} ; \mathrm{Vte} / \mathrm{Te}$, mean expiratory flow.

inconsistent results. ${ }^{3-20}$ In these studies, one of the obvious methodological issues existed with respect to the selection of exhalation valve connected to the single-limb circuit. PEV or NRV have been shown to be more effective in eliminating $\mathrm{CO}_{2}$ rebreathing in patients at rest, ${ }^{21}$ however, because NRV has the disadvantages of increased expiratory resistance and work of breathing ${ }^{22}$ and potential malfunction, $\mathrm{PEV}$ has been

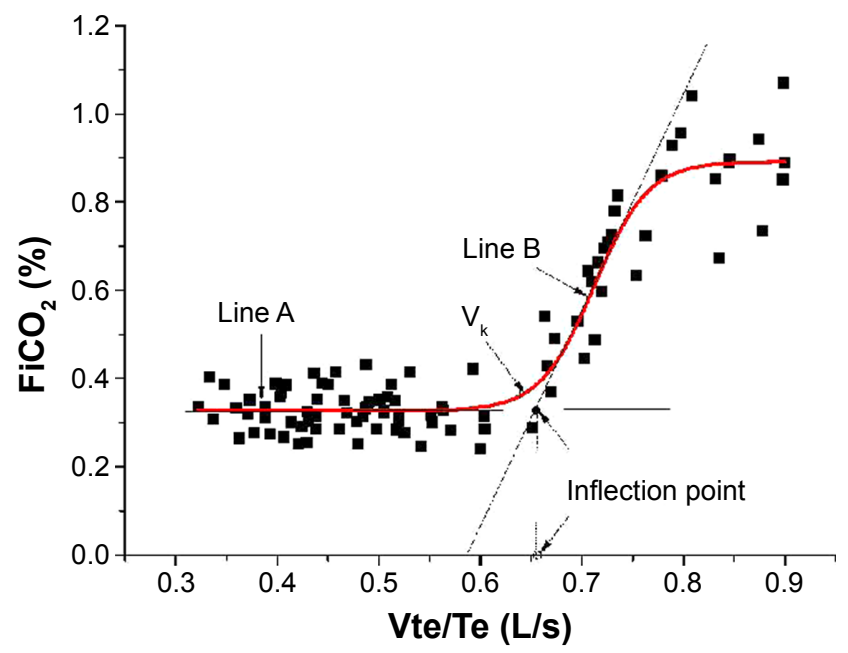

Figure 4 Typical example of analysis of nonlinear curve fitness of mean expiratory flow-tidal $\mathrm{FiCO}_{2}$ curve.

Notes: The filled square $(\square)$ on the fitted curve (thick line) represents $V_{k}$ which divides the curve to yield the best fit of two lines (A and B, thin lines). Closed circle (•) represents the calculated inflection point.

Abbreviations: $\mathrm{FiCO}_{2}$, fractional concentration of inspired $\mathrm{CO}_{2}$; Vte/Te, mean expiratory flow. widely used. In the single-limb tubing for inspiration and expiration, $\mathrm{PEV}$ serves to eliminate $\mathrm{CO}_{2}$ from the breathing circuit and is an important part for decreasing dead space ventilation and improving ventilation efficiency. Former studies have found that leak flow rates of PEV remained nearly constant throughout the specified pressure range. ${ }^{23}$ With the increasing minute ventilation during exercise, NIV with a PEV might cause $\mathrm{CO}_{2}$ rebreathing. As far as we know through the search of Medline, there has been no report on evaluating $\mathrm{CO}_{2}$ rebreathing in COPD patients assisted by NIV in BiPAP mode with a PEV on single-limb circuit during maximal cycle exercise test.

The main findings of this study are as follows: 1) during exercise, with the increasing total expiratory flow of the subject, the flow vented out of PEV decreased (Figure 2); 2) compared to at rest, tidal $\mathrm{FiCO}_{2}$ increased significantly at peak exercise in COPD patients $(P<0.01)$, indicating $\mathrm{CO}_{2}$ rebreathing occurred; 3 ) ventilated by a single-limb tubing with PEV during exercise, patients with Vte/Te $>0.67 \pm 0.09 \mathrm{~L} / \mathrm{s}(95 \% \mathrm{CI}: 0.60-0.73 \mathrm{~L} / \mathrm{s})$ may be predisposed to a higher risk of $\mathrm{CO}_{2}$ rebreathing.

With regard to patients with severe COPD ventilated by a single-limb tubing during exercise, obvious methodological issues existed and they resulted in inconsistent outcomes for relieving dyspnea or improving exercise tolerance. Different exhalation valves and different levels of pressure support have 
been reported. In previous studies, investigating the effects of a single-limb circuit with a Silentflow Exhalation valve (Weinmann, Hamburg, Germany) to deliver ventilatory assistance (IPAP: $29.5 \pm 4.1 \mathrm{cmH}_{2} \mathrm{O}$, EPAP: $4.38 \pm 0.82 \mathrm{cmH}_{2} \mathrm{O}$ ) during exercise in COPD with hypercapnia, ${ }^{16,17}$ there were controversial outcomes on the alleviation of dyspnea. Moreover, in studies by Moga et $\mathrm{al}^{19}$ and Highcock et al, ${ }^{20}$ they found that BiPAP with Whisper Swivel II did not improve exercise capacity. These findings, in combination with the result found by Ferguson and Gilmartin ${ }^{21}$ that significant $\mathrm{CO}_{2}$ rebreathing could occur at low expiratory pressure levels $\left(\leq 4 \mathrm{cmH}_{2} \mathrm{O}\right)$ on single-limb circuit with Whisper Swivel Valve or other fixed-resistance exhalation devices, suggested that $\mathrm{CO}_{2}$ may not be adequately cleared with the fixed-resistance exhalation valve both at rest and during exercise and that this blunted the efficacy of NIV. Former study has implied that such $\mathrm{CO}_{2}$ rebreathing and dead space ventilation could be effectively eliminated by the use of NRV or the PEV. ${ }^{21}$ However, NRV eliminated $\mathrm{CO}_{2}$ at the expense of increasing expiratory resistance and work of breathing, ${ }^{22}$ and sometimes it can potentially malfunction; considering these factors, PEV has been the most widely used. NIV with single-limb circuit in BiPAP mode is often used, ${ }^{11-17}$ pressure support (PS) setting of $10 \mathrm{cmH}_{2} \mathrm{O}$ has been proven to be effective to reduce dyspnea in COPD patients, ${ }^{4,5,18}$ and based on the mechanism of action of $\mathrm{PEV}$, leak flow rates were greater at around 4-5 $\mathrm{cmH}_{2} \mathrm{O}$, therefore, single-limb tubing with PEV in BiPAP mode with PS setting of $10 \mathrm{cmH}_{2} \mathrm{O}$ (IPAP:EPAP $14: 4 \mathrm{cmH}_{2} \mathrm{O}$ ) was used in this study.

As to the measurement of $\mathrm{CO}_{2}$ rebreathing, some research indicated a preference for measurement of $\mathrm{CO}_{2}$ partial pressure in an arterial blood gas sample $\left(\mathrm{PaCO}_{2}\right),{ }^{21,22}$ whereas others argued that the value of $\mathrm{CO}_{2}$ inhaled $\left(\mathrm{FiCO}_{2}\right)^{33-35}$ offered more accurate and beneficial information. In fact, these values could be regarded as interdependent values. According to our point of view, $\mathrm{FiCO}_{2}$ is the most representative value in rebreathing as it shows the $\mathrm{CO}_{2}$ amount in the patient's mask at the proto-inspiratory phase. It was shown that during exercise, with the increase of expiratory tidal volume, elevated breathing frequency, and Vte/Te, and the decrease of $\mathrm{Ex} / \mathrm{Te}$, tidal $\mathrm{FiCO}_{2}$ significantly increased (Table 2), indicating that $\mathrm{CO}_{2}$ rebreathing occurred during exercise in this setting, which needs to be paid attention to.

Understanding the mechanisms related to the occurrence of $\mathrm{CO}_{2}$ rebreathing is important. $\mathrm{CO}_{2}$ rebreathing consists of rebreathing previously expired gas by the patient if such gas is not appropriately eliminated from the circuit during the ventilatory cycle, as a result of an accumulation of this gas in the circuit. $\mathrm{CO}_{2}$ rebreathing takes place mainly in single-limb circuits. Besides, the type of mask and expiratory port, ${ }^{23,33,34,36-38}$ and the level of EPAP used, ${ }^{21,34}$ end-tidal $\mathrm{CO}_{2}$ concentration $\left(\mathrm{EtCO}_{2}\right), \mathrm{RR}$, tidal volume $(\mathrm{Vt})$, were also the factors influencing $\mathrm{CO}_{2}$ rebreathing. ${ }^{35}$ However, the increasing level of EPAP was not as important as fixedresistance exhalation devices since the leak flow rate of PEV was greater at $\sim 4-5 \mathrm{cmH}_{2} \mathrm{O}$. During exercise, with the use of single-limb circuit with a PEV and nonvented mask, with the increasing $\mathrm{Vt}, \mathrm{RR}$, and $\mathrm{EtCO}_{2}$, these could predispose patients to $\mathrm{CO}_{2}$ rebreathing.

However, in this study, three of the COPD patients with their $\mathrm{FEV}_{1}$ of $0.49,0.52$, and $0.61 \mathrm{~L}$ failed the curve fitness (adjusted $R^{2}<0.05$; Figure $3 \mathrm{~B}$ ), suggesting that there was no $\mathrm{CO}_{2}$ rebreathing. As their $\mathrm{FEV}_{1}$ (the maximum amount of air a person can expel in $1 \mathrm{~s}$ of forceful exhalation) were lower or within the inflection point $(0.60-0.73 \mathrm{~L} / \mathrm{s})$, this in some extent supports our results. To ensure that no exhaled gas remains in the tubing at the end of expiration, the Vte/Te has to be lower than the intentional leak obtained through PEV (0.39-0.41 L/s) during expiration. Therefore, in some pulmonary rehabilitation programs, with the setting of pressure support similar to our study, with the increasing Vte/Te, it may not be suitable for patients whose $\mathrm{FEV}_{1}$ exceeds $0.73 \mathrm{~L}$ to be included; it might be indicated as a reference value for patient inclusion in pulmonary rehabilitation programs with similar study setting.

This study has some limitations which need to be addressed. On the one hand, a limitation of this study is its small number of study patients. However, in this study, we have compared a large number of individual breaths for each respective subject. The comparison of individual breaths, rather than for example patients, is appropriate since the amount of rebreathing may depend on numerous factors, such as $\mathrm{Vt}$, and timing of the respiratory cycle ( $\mathrm{RR}$ and inspiratory duty cycle). Most of these exhibited large variations (in the same patient) on a breath-by-breath basis during spontaneous breathing with pressure support.

On the other hand, a nonlinear curve fit was applied to the scatter plot, $\mathrm{CO}_{2}$ rebreathing inflection point was determined based on the nonlinear curve fit, and it was an indirect and rough estimation. $R^{2}$ is a number that indicates how well data fits a curve. In practice, an adjusted $R^{2}$ was usually close to 1 if the curve perfectly fitted the data and close to 0 when the curve did not fit the data at all, so the choice of 0.8 of $R^{2}$ was not critical. However, with the increase of ventilatory requirement, expiratory tidal volume, elevated breathing frequency and $\mathrm{Vte} / \mathrm{Te}$, tidal $\mathrm{FiCO}_{2}$ increased significantly, 
indicating that obvious $\mathrm{CO}_{2}$ rebreathing existed in the singlelimb circuit.

Since $\mathrm{CO}_{2}$ rebreathing increased respiratory motor output, ventilation and work of breathing, reducing the efficiency of NIV to assist exercise, ${ }^{24,25}$ the current authors would suggest that the present findings would help design future studies on NIV-assisted exercise in COPD patients. First, our group previously found that $\mathrm{CO}_{2}$ rebreathing could be minimized in COPD patients treated with NIV with the path of exhalation connected to the side hole on the mask at rest. In order to avoid $\mathrm{CO}_{2}$ rebreathing, maybe such a setup modification could be used during exercise. ${ }^{23}$ Second, an NRV applied on the single-limb during exercise will also be worth testing in future study. Third, use of double-limb ventilatory circuit other than the PEV to prevent $\mathrm{CO}_{2}$ rebreathing should be considered during BiPAP ventilatory assistance.

\section{Conclusion}

Our results indicated that ventilatory assistance delivered in BiPAP mode with PS setting of $10 \mathrm{cmH}_{2} \mathrm{O}$ (IPAP:EPAP 14:4 $\mathrm{cmH}_{2} \mathrm{O}$ ) with single-limb tubing with PEV during exercise could produce significant $\mathrm{CO}_{2}$ rebreathing. $\mathrm{CO}_{2}$ rebreathing should be paid attention to in the pulmonary rehabilitation exercise programs that deliver bi-level pressure support ventilation with a single-limb circuit with PEV.

\section{Acknowledgments}

The authors thank colleagues from the pulmonary function test room (Division of Respiratory Diseases Department, Guangzhou Institute of Respiratory Disease, First Affiliated Hospital of Guangzhou Medical University, People's Republic of China) for their collaboration, and Doctors Yi Gao, Wei-jie Guan, and Li-ping Zhong for technical support.

\section{Funding}

This research did not receive any specific grant from funding agencies in the public, commercial, or not-for-profit sectors.

\section{Disclosure}

The authors report no conflicts of interest in this work.

\section{References}

1. Spruit MA, Singh SJ, Garvey C, et al. An official American Thoracic Society/European Respiratory Society statement: key concepts and advances in pulmonary rehabilitation. Am J Respir Crit Care Med. 2013; 188(8):e13-e64.

2. Maltais F, LeBlanc $\mathrm{P}$, Jobin J, et al. Intensity of training and physiologic adaptation in patients with chronic obstructive pulmonary disease. Am J Respir Crit Care Med. 1997;155(2):555-561.
3. van't Hul A, Kwakkel G, Gosselink R. The acute effects of noninvasive ventilatory support during exercise on exercise endurance and dyspnea in patients with chronic obstructive pulmonary disease: a systematic review. J Cardiopulm Rehabil. 2002;22(4):290-297.

4. van't Hul A, Gosselink R, Hollander P, Postmus P, Kwakkel G. Acute effects of inspiratory pressure support during exercise in patients with COPD. Eur Respir J. 2004;23(1):34-40.

5. van't Hul A, Gosselink R, Hollander P, Postmus P, Kwakkel G. Training with inspiratory pressure support in patients with severe COPD. Eur Respir J. 2006;27(1):65-72.

6. Corner E, Garrod R. Does the addition of non-invasive ventilation during pulmonary rehabilitation in patients with chronic obstructive pulmonary disease augment patient outcome in exercise tolerance? a literature review. Physiother Res Int. 2010;15(1):5-15.

7. Nickol AH, Hart N, Hopkinson NS, et al. Mechanisms of improvement of respiratory failure in patients with COPD treated with NIV. Int $J$ Chron Obstruct Pulmon Dis. 2008;3(3):453-462.

8. Chen H, Liang BM, Xu ZB, et al. Long-term non-invasive positive pressure ventilation in severe stable chronic obstructive pulmonary disease: a meta-analysis. Chin Med J (Engl). 2011;124(23):4063-4070.

9. Bianchi L, Foglio K, Porta R, Baiardi R, Vitacca M, Ambrosino N. Lack of additional effect of adjunct of assisted ventilation to pulmonary rehabilitation in mild COPD patients. Respir Med. 2002;96(5):359-367.

10. Hawkins P, Johnson LC, Nikoletou D, et al. Proportional assist ventilation as an aid to exercise training in severe chronic obstructive pulmonary disease. Thorax. 2002;57(10):853-859.

11. Johnson JE, Gavin DJ, Adams-Dramiga S. Effects of training with heliox and noninvasive positive pressure ventilation on exercise ability in patients with severe COPD. Chest. 2002;122(2):464-472.

12. Reuveny R, Ben-Dov I, Gaides M, Reichert N. Ventilatory support during training improves training benefit in severe chronic airway obstruction. Isr Med Assoc J. 2005;7(3):151-155.

13. Borghi-Silva A, Di Thommazo L, Pantoni CB, Mendes RG, Salvini Tde F, Costa D. Non-invasive ventilation improves peripheral oxygen saturation and reduces fatigability of quadriceps in patients with COPD. Respirology. 2009;14(4):537-544.

14. Borghi-Silva A, Mendes RG, Toledo AC, et al. Adjuncts to physical training of patients with severe COPD: oxygen or noninvasive ventilation? Respir Care. 2010;55(7):885-894.

15. Toledo A, Borghi-Silva A, Sampaio LM, Ribeiro KP, Baldissera V, Costa $\mathrm{D}$. The impact of noninvasive ventilation during the physical training in patients with moderate-to-severe chronic obstructive pulmonary disease (COPD). Clinics (Sao Paulo). 2007;62(2):113-120.

16. Dreher M, Storre JH, Windisch W. Noninvasive ventilation during walking in patients with severe COPD: a randomised cross-over trial. Eur Respir J. 2007;29(5):930-936.

17. Dreher M, Doncheva E, Schwoerer A, et al. Preserving oxygenation during walking in severe chronic obstructive pulmonary disease: noninvasive ventilation versus oxygen therapy. Respiration. 2009;78(2): 154-160.

18. Keilty SE, Ponte J, Fleming TA, Moxham J. Effect of inspiratory pressure support on exercise tolerance and breathlessness in patients with severe stable chronic obstructive pulmonary disease. Thorax. 1994;49(10): 990-994.

19. Moga AM, de Marchie M, Saey D, Spahija J. Bi-level Positive Airway Pressure (BiPAP) with standard exhalation valve does not improve maximum exercise capacity in patients with COPD. COPD. 2015;12(1): $46-54$.

20. Highcock MP, Shneerson JM, Smith IE. Increased ventilation with NiIPPV does not necessarily improve exercise capacity in COPD. Eur Respir J. 2003;22(1):100-105.

21. Ferguson GT, Gilmartin M. CO2 rebreathing during BiPAP ventilatory assistance. Am J Respir Crit Care Med. 1995;151(4):1126-1135. 
22. Lofaso F, Brochard L, Touchard D, Hang T, Harf A, Isabey D. Evaluation of carbon dioxide rebreathing during pressure support ventilation with airway management system (BiPAP) devices. Chest. 1995;108(3): $772-778$.

23. Chen R, Zhang X, He G. [Modification of facial mask on the dead space effect in non-invasive mask ventilation]. Zhonghua Jie He He Hu Xi Za Zhi. 2000;23(12):734-736. Chinese.

24. Scheid P, Lofaso F, Isabey D, Harf A. Respiratory response to inhaled CO2 during positive inspiratory pressure in humans. J Appl Physiol. 1994; 77(2):876-882.

25. Georgopoulos D, Mitrouska I, Bshouty Z, Webster K, Patakas D, Younes M. Respiratory response to $\mathrm{CO} 2$ during pressure-support ventilation in conscious normal humans. Am J Respir Crit Care Med. 1997; 156(1):146-154.

26. Hill NS. Noninvasive ventilation. Does it work, for whom, and how? Am Rev Respir Dis. 1993;147(4):1050-1055.

27. Brochard L. Non-invasive ventilation: practical issues. Intensive Care Med. 1993;19(8):431-432.

28. Miller MR, Hankinson J, Brusasco V, et al. Standardisation of spirometry. The Eur Respir J. 2005;26(2):319-338.

29. Crapo RO, Morris AH, Clayton PD, Nixon CR. Lung volumes in healthy nonsmoking adults. Bull Eur Physiopathol Respir. 1982;18(3): 419-425.

30. Morris JF, Koski A, Temple WP, Claremont A, Thomas DR. Fifteenyear interval spirometric evaluation of the Oregon predictive equations. Chest. 1988;93(1):123-127.
31. Briscoe WA, Dubois AB. The relationship between airway resistance, airway conductance and lung volume in subjects of different age and body size. J Clin Invest. 1958;37(9):1279-1285.

32. Lucangelo U, Blanch L. Dead space. Intensive Care Med. 2004;30(4): 576-579.

33. Taccone P, Hess D, Caironi P, Bigatello LM. Continuous positive airway pressure delivered with a "helmet": effects on carbon dioxide rebreathing. Crit Care Med. 2004;32(10):2090-2096.

34. Samolski D, Calaf N, Guell R, Casan P, Anton A. Carbon dioxide rebreathing in non-invasive ventilation. Analysis of masks, expiratory ports and ventilatory modes. Monaldi Arch Chest Dis. 2008;69(3): 114-118.

35. Szkulmowski Z, Belkhouja K, Le QH, Robert D, Argaud L. Bilevel positive airway pressure ventilation: factors influencing carbon dioxide rebreathing. Intensive Care Med. 2010;36(4):688-691.

36. Schettino GP, Chatmongkolchart S, Hess DR, Kacmarek RM. Position of exhalation port and mask design affect $\mathrm{CO} 2$ rebreathing during noninvasive positive pressure ventilation. Crit Care Med. 2003;31(8): 2178-2182.

37. Racca F, Appendini L, Gregoretti C, et al. Effectiveness of mask and helmet interfaces to deliver noninvasive ventilation in a human model of resistive breathing. J Appl Physiol (1985). 2005;99(4):1262-1271.

38. Racca F, Appendini L, Gregoretti C, et al. Helmet ventilation and carbon dioxide rebreathing: effects of adding a leak at the helmet ports. Intensive Care Med. 2008;34(8):1461-1468.
International Journal of COPD

\section{Publish your work in this journal}

The International Journal of COPD is an international, peer-reviewed journal of therapeutics and pharmacology focusing on concise rapid reporting of clinical studies and reviews in COPD. Special focus is given to the pathophysiological processes underlying the disease, intervention programs, patient focused education, and self management protocols.

\section{Dovepress}

This journal is indexed on PubMed Central, MedLine and CAS. The manuscript management system is completely online and includes a very quick and fair peer-review system, which is all easy to use. Visit $\mathrm{http} / / / \mathrm{www}$.dovepress.com/testimonials.php to read real quotes from published authors. 